\title{
Racial Gaps, Occupational Matching, and Skill Uncertainty
}

\author{
Limor Golan and Carl Sanders
}

White workers in the United States earn almost 30 percent more per hour on average than Black workers, and this wage gap is associated with large racial differences in occupational assignments. In this article, we theoretically and empirically examine the Black-White disparity in occupations. First, we present a model based on Antonovics and Golan (2012) that relates occupational assignments to the incentives workers face while learning about their own unknown ability. Second, we document differences between Black and White workers in both the complexity of skills required in their initial occupations and the growth rates of this complexity over time. To do this, we match panel data from the National Longitudinal Survey of Youth 1979 with the Dictionary of Occupational Titles measures of occupational characteristics and find that, compared with White workers, Black workers start in occupations requiring less-complex skills, see slower growth in job complexity over time, and are relatively more likely to transition to jobs with lower complexity. Finally, we consider the relationship between our model and our empirical findings; for example, discrimination in hiring early in the career can have long-term consequences on the ability of Black workers to learn their best occupational match and explains part of their lower wage growth. We conclude with suggestions for policy and future research directions. (JEL J01, J24, J31)

Federal Reserve Bank of St. Louis Review, Second Quarter 2019, 101(2), pp. 135-53. https://doi.org/10.20955/r.101.135-53

\section{INTRODUCTION}

The labor market experiences of Black and White workers in the United States are dramatically different. A first-order difference is the well-documented racial wage gap: The average hourly wage for White workers is 30 percent higher than for Black workers. This racial wage gap has been shown to reflect differences in both socioeconomic backgrounds and discriminatory practices in the labor market and has created a sizable literature across multiple disciplines. But differences in earnings do not exhaust the racial differences in labor market experiences. In this article, we consider racial gaps in workers' occupations, that is, differences in what

Limor Golan is an associate professor at Washington University in St. Louis and a research fellow at the Federal Reserve Bank of St. Louis. Carl Sanders is an assistant professor at Washington University in St. Louis.

(c) 2019, Federal Reserve Bank of St. Louis. The views expressed in this article are those of the author(s) and do not necessarily reflect the views of the Federal Reserve System, the Board of Governors, or the regional Federal Reserve Banks. Articles may be reprinted, reproduced, published, distributed, displayed, and transmitted in their entirety if copyright notice, author name(s), and full citation are included. Abstracts, synopses, and other derivative works may be made only with prior written permission of the Federal Reserve Bank of St. Louis. 
White and Black workers do rather than what they earn. Even the most basic descriptive statistics show large differences between Black and White workers in the types of work they perform. For example, Black workers were 12 percent of the working population in 2016 and made up 26 percent of the occupation "truck and tractor operators," while making up only 3 percent of "chief executives." White workers showed the opposite pattern, making up 45 percent of the working population in 2016 and 85 percent of chief executives. 1

Our focus on racial differences in occupations is consistent with recent work in empirical labor economics, which links differences in occupations and occupational mobility to workers' wage growth. It is often more informative to know someone's occupational title than their current wage: taking two young workers who each earn $\$ 15$ an hour, the knowledge that one has the occupation "accountant" and the other "refrigeration mechanic" helps to make the (on average correct) prediction that the accountant will make significantly more than the mechanic 10 years later. Understanding the reasons Black and White workers take different occupations can provide insight into differences in wage levels and wage growth.

The primary contribution of this article is documenting and interpreting the differences in the relative occupational assignments of Black and White workers. In the first part of the study, we present an economic model to use as a framework for interpreting our empirical results on occupational choice, occupational turnover, and wage growth. In the second section, we document the racial gaps in occupational choice in representative U.S. data, looking both at aggregate trends in occupational choice within a worker's career and at occupation-tooccupation transition rates. Finally, in our empirical results, we compare the predictions of the model to our descriptive findings and discuss the implications of the underlying economic mechanisms for policy and future research.

Section 2 of our article gives a framework to interpret occupational mobility across races as the result of different economic circumstances. Our model is a learning model following Antonovics and Golan (2012) that is capable of generating occupational mobility and wage growth across the career. For simplicity, we present analysis of a two-period model. Each period, workers choose an occupation to maximize the expected present discounted value of lifetime income, but occupational choice is complicated by the fact that workers do not know their own ability and thereby their best occupational match. Working allows a worker to learn about his ability over time, but different jobs give information about the worker's skills at different rates.

The amount that workers learn about their skills depends on the intensity of their job. Different jobs require performance of tasks that require varying intensities of unobservable skills. The more output depends on the unobserved skills, the more information the job reveals about those skills. For example, workers learn more about their ability as a manager in management jobs. Information about skill levels may increase future earnings because it allows a better assignment of workers to jobs. Thus, workers experiment, forgoing expected current-period output in order to learn about their skills by taking jobs they would not take otherwise. Antonovics and Golan's (2012) results show that the optimal level of experimentation is initially small, increases as workers gain experience, and then declines as workers become increasingly certain about their skills. 
Mapping the theoretical concept of "occupational intensity" to the data requires nonstandard measures, since in Census-like data sets only the occupational title is recorded rather than any specific on-the-job activities. To overcome this data limitation, we use data on occupational characteristics from the Dictionary of Occupational Titles (DOT) merged with workerlevel panel data from the National Longitudinal Survey of Youth 1979 (NLSY79). We use the detailed occupation-level characteristics from the DOT to reduce the unordered list of occupational titles into a single-dimensional index that ranks occupations by the degree to which output depends on skills that are difficult to observe directly, e.g., creativity. This index ranks occupations with respect to the dependence of output on skills that are hard to observe, which we call "complexity" throughout for brevity.

In Section 3, we analyze the merged data sets and show that, as expected, the average White worker's first occupation tends to be more-complex than the average Black worker's first occupation. Moreover, over a career, the average White worker's occupational complexity grows faster than the average Black worker's. Further empirical analysis considers whether these differences are driven by rates of occupational switching, differences in the promotion rates of less- versus more-complex occupations, and the role of demographic characteristics and education in explaining these occupational gaps.

When we look more closely at the rates of occupational switching, we find that the slower pattern of occupational upgrading by Black workers relative to White workers is not driven by lower occupational mobility. Rather, Blacks are marginally more likely to switch occupations than Whites, but a greater proportion of Black occupational transitions are "downgrades," that is, switches toward occupations characterized by lower levels of complexity. Given an occupational switch, White workers make an occupational upgrade 54 percent of the time, compared with 51 percent for Black workers.

Regarding potential average demographic differences between races, we examine to what extent differences in workers' first occupations and the growth rate of occupational complexity are driven by race alone rather than other explanations. For example, Black workers may begin in less-complex occupations on average more often than White workers due simply to average differences in education levels. We find that racial differences in the speed of occupational upgrading persist even if we consider White and Black workers who are originally in the same occupation. This finding suggests that race-specific factors such as discrimination might partially explain differences in occupational transition rates.

Additionally, we consider the first job that workers have and find that controlling for measurable demographics such as education level and test scores does not eliminate the effect of race on the initial occupational assignment: Black workers with seemingly very similar skills as White workers tend to work in less-complex occupations. Our economic model suggests that if Black workers are discriminated against in hiring for high-complexity occupations, it can have long-term effects on their occupational complexity and wage growth relative to White workers.

From a policy perspective, one of the major issues surrounding racial labor market gaps is the question of mismatch. Workers may not always be well matched to their job or occupation, and if demographic background differences and racial discrimination make this problem 
more severe, there may be large productivity gains by improving the match of Black workers with their best occupations. In this article, we focus on the role of mismatch induced by informational frictions in the Black-White wage gap. Even if there were no barriers to hiring or finding jobs, workers and employers do not always have complete information about the worker's skills or the suitability of those skills to the tasks required by the job. Over time, as a worker comes to know his or her own skills and the employer observe the worker's performance, both the worker and the employer both could learn about the worker's ability and comparative advantage. Based on this information, workers change jobs and, over time, wages grow because workers work in occupations and jobs in which they are better matched. Policies that aim to improve the information available to both workers and employers could potentially reduce the costs of mismatch and, and if discrimination in occupational attainment leads to Black workers receiving less information about their skills over their careers, it may be necessary to target these policies to Black workers.

The remainder of the article is organized as follows: In Section 2 we review the literature on labor learning models and racial labor market gaps; in Sections 3 and 4 we set up and solve the two-period learning model; in Section 5 we describe worker and occupational data construction; in Section 6 we present the empirical results; and in Section 7 we present conclusions.

\section{RELATED LITERATURE}

The theoretical and empirical literature on uncertainty in the labor market primarily focuses on models of matching (see, for example, Jovanovic, 1979, and Miller, 1984) and models of learning (see, for example, Farber and Gibbons, 1996; Gibbons and Waldman, 1999; Neal, 1999; and Gibbons et al., 2005). There is also a set of empirical labor papers that analyze how workers and firms learn about unobserved ability and how quickly this happens (see Miller, 1984; Pastorino, 2009; Papageorgiou, 2014; James, 2012; Sanders, 2017; and Golan et al., 2017).

There is a large literature on Black-White pay gaps as well as other racial differences in labor market outcomes. The economics literature emphasizes the importance of pre-market factors in these differences in outcomes. See Altonji and Blank (1999), Cameron and Heckman (2001), Carneiro et al. (2005), and Fryer (2011) for surveys of economic analyses of racial labor market gaps, including the empirical relationships between pre-market characteristics such as education, test scores, and family background, with a variety of labor market outcomes. There has been less recent focus on the role of post-market entry differences in the experiences of Black and White workers. The fact that similar Black and White workers are employed at different rates was originally discussed in the context of long-term trends in racial wage gaps: Brown (1984), Chandra (2000), Juhn (2003), and Western and Pettit (2005) all found evidence that more Black workers than White workers dropped out of the labor force between 1940 and 1990, and higher-wage Black workers were more likely to drop out than higher-wage White workers, increasing the measured wage gap. In the context of a single cohort, Eckstein and Wolpin (1999) emphasize the difference between actual and potential wage-offer distributions, making the point that observed wages can either under- or over-estimate discrimination. 
Antecol and Bedard (2004) find that including measures of actual (rather than potential) labor market experience closes even more of the gap in the Neal and Johnson (1996)-type wage specification.

There are other economic theories of racial wage gaps that do not require systematic differences in average skills. For example, Oettinger (1996) develops and tests a model of statistical discrimination, where assuming Blacks have less-precise signals of ability predicts an increasing wage gap with experience, even if both races have equal mean ability. He finds that Blacks have lower gains to mobility, which causes the Black-White wage gap to rise with experience. Altonji and Pierret (2001) develop a test for statistical discrimination and do not find evidence supporting the hypothesis that employers discriminate based on easily observed characteristics such as education.

This article focuses on describing the patterns in the occupational choices and job transitions of Black and White individuals. While there is a growing literature relating occupational choices of workers, tasks performed, and data on occupational skill requirements (see Sanders and Taber, 2012, for a review of the literature on heterogeneous/multidimensional human capital, which often uses task-based data), the labor literature on job tasks has not typically focused on cross-race differences in labor force outcomes. Golan et al. (2017), a complementary paper, develops a generalized life-cycle model that includes occupational sorting, job turnover, multidimensional skill gaps, and taste differences, and quantifies the magnitude of the different factors accounting for the life-cycle racial gaps in earnings, participation, and occupational choices.

\section{MODEL}

The model presented was developed in Antonovics and Golan (2012). We consider a two-period economy with risk-neutral workers and firms with a common discount factor $\delta$. Workers differ in the sets of skills they possess. We examine a simple scenario in which each worker has only two skills: a known skill, $k$, and an unknown skill, $\theta$, both of which are time invariant. For simplicity we assume that each firm offers one job. Each job differs in the extent to which output depends on $k$ and $\theta$. There is a continuum of jobs, $j$, each completely characterized by a given value of $\alpha^{j} \in[0,1]$, where $\alpha$ denotes the degree to which output depends on $\theta$ relative to $k$. Thus, choosing a job in period $t$ is equivalent to choosing a value of $\alpha$. Given this choice, we assume output in period $t$ is given by

$$
y_{t}=\alpha_{t} \theta+\left(1-\alpha_{t}\right) k+\varepsilon_{t}
$$

where $\varepsilon_{t}$ are independent and identically distributed productivity shocks and $\alpha_{t}$ is the value of $\alpha$ chosen by the worker at time $t$. Note that there is one job in which output is sensitive only to $\theta(\alpha=1)$ and one job in which output is sensitive only to $k(\alpha=0)$. For the rest of the jobs, the higher is $\alpha^{j}$, the more output depends on $\theta$.

Information in the model is symmetric; firms and workers have common priors on $\theta$, $k$ is known to everyone, and output is commonly observed. Workers and firms acquire addi- 
tional information about a worker's unknown skill through successive observations of output. Thus, having observed output, workers and firms calculate

$$
x_{t}=\frac{y_{t}-\left(1-\alpha_{t}\right) k}{\alpha_{t}}=\theta+\frac{\varepsilon_{t}}{\alpha_{t}},
$$

where $x_{t}$ serves as a signal of the worker's unobserved skill, $\theta$. The noise in $x_{t}$ is not independent of a worker's job choice. In particular, the higher is $\alpha_{t}$, the higher is the signal-to-noise ratio and the more information about $\theta$ the market is able to extract from $x_{t}$. Under the assumption that the prior distribution of $\theta$ at time $t$ is normal with mean $\mu_{t}$ and variance $\sigma_{t}^{2}$ and the distribution of $\varepsilon_{t}$ is normal with mean zero and variance $\sigma_{\varepsilon}^{2}$, the posterior distribution of $\theta$ is known to be normal with mean $\mu_{t+1}$ and variance $\sigma_{t+1}^{2}$, where

$$
\mu_{t+1}=\frac{\mu_{t} \sigma_{\tilde{\varepsilon}, t}^{2}+x_{t} \sigma_{t}^{2}}{\sigma_{\tilde{\varepsilon}, t}^{2}+\sigma_{t}^{2}}
$$

and

$$
\sigma_{t+1}^{2}=\frac{\sigma_{\tilde{\varepsilon}, t}^{2} \sigma_{t}^{2}}{\sigma_{t}^{2}+\sigma_{\tilde{\varepsilon}, t}^{2}}
$$

and where $\sigma_{\tilde{\varepsilon}, t}^{2}=\frac{\sigma_{\varepsilon}^{2}}{\alpha_{t}^{2}}$. In addition, $\mu_{t+1}$ is itself normally distributed with mean $m_{t+1}$ and variance $s_{t+1}^{2}$ given by

$$
\begin{gathered}
m_{t+1}=\mu_{t} \\
s_{t+1}^{2}=\frac{\sigma_{t}^{4}}{\sigma_{t}^{2}+\sigma_{\tilde{\varepsilon}, t}^{2}} .
\end{gathered}
$$

Thus, the posterior mean of $\theta$ follows a martingale and the more information $x_{t}$ reveals about $\theta$ (the higher is $\alpha$ ), the higher is the variance of the posterior mean.

We assume competitive markets and free entry into the labor market. Thus, wages are the expected productivity in each period.

Workers' current-period utility is given by $U_{t}=w_{t}$ so workers choose $\alpha_{t}$ to maximize the expected present discounted value of lifetime wages.

\subsection{Optimal Job Choice}

Workers work for two periods and then retire. Thus, the worker's problem can be written as

$$
V\left(\mu_{1}, \sigma_{1}^{2}\right)=\max _{\alpha_{t} \in[0,1]} \alpha_{1} \mu_{1}+\left(1-\alpha_{1}\right) k+\delta E_{1}\left[\alpha_{2} \mu_{2}+\left(1-\alpha_{2}\right) k\right]
$$

which we can solve recursively beginning from the second period.

The second-period optimal choice of job is given by

$$
\alpha_{2}\left(\mu_{2}\right)= \begin{cases}1, & \text { if } \mu_{2} \geq k \\ 0, & \text { otherwise }\end{cases}
$$


The second-period job assignment is simply to choose the job in which the wage is the highest.

Solving backwards, we first solve for the optimal assignment in period one. Note that expected productivity in period two depends on the second-period belief, $\mu_{2}$, which in turn depends on $\alpha_{1}$ through $x_{1}$ (see equations (2) and (3)). We therefore rewrite the first-period problem as

$$
V\left(\mu_{1}, \sigma_{1}^{2}\right)=\max _{\alpha_{1} \in[0,1]} \alpha_{1} \mu_{1}+\left(1-\alpha_{1}\right) k+\delta\left[\Phi(r) k+\int_{k}^{\infty} \mu_{2} f\left(\mu_{2}\right) d \mu_{2}\right],
$$

where $r=\frac{k-\mu_{1}}{s_{2}}, \Phi(\cdot)$ is the standard normal cumulative density function and $f$ is the normal probability density function with mean $m_{2}=\mu_{1}$ and variance $s_{2}^{2}=\frac{\alpha_{1}^{2} \sigma_{1}^{4}}{\alpha_{1}^{2} \sigma_{1}^{2}+1}$. The above equation makes clear that when $\mu_{1}<k$, there is a cost associated with selecting $\alpha_{1}>0$ since expected current-period output will be less than $k$. Thus, when $\mu_{1}<k$, workers must weigh the benefit of increasing $\alpha_{1}$ in terms of expected second-period output against the cost in terms of expected current-period output.

The second-period output is increasing in $\alpha_{1}$. The expected value of any left-truncated normal random variable is increasing in the variance of that random variable. Thus, since $s_{2}^{2}$ is increasing in $\alpha_{1}$, we know that expected second-period output must also be increasing in $\alpha_{1}$. Intuitively, information is valuable because workers can truncate the loss if they receive a negative signal about $\theta$ by selecting future jobs with $\alpha=0$, but can take advantage of the arrival of positive information about $\theta$ by selecting jobs with $\alpha=1$.

We say that a worker experiments if a worker chooses to forego expected current-period wages in order to gain information about $\theta$, that is, if a worker with $\mu_{1}<k$ chooses $\alpha_{1}>0$. Proposition 2 in Antonovics and Golan (2012) establishes that for every value of beliefs $\mu_{1}<k$, there exists a prior variance $\sigma^{2}$, so it is optimal to choose $\alpha>0$. That is, experimentation is beneficial if there is sufficient uncertainty about a worker's skill. Intuitively, even when $\theta$ is believed to be very low, if there is sufficient uncertainty about $\theta$, then the probability that $\theta>k$ is high enough that it is worth foregoing current-period output to gain additional information about $\theta$ 's true value.

The first-order necessary condition for an interior solution is

$$
\frac{\partial \phi(r)}{\partial \alpha_{1}} s_{2}+\frac{\partial s_{2}}{\partial \alpha_{1}} \phi(r)+\left(k-\mu_{1}\right) \frac{\partial \Phi(r)}{\partial \alpha_{1}}=\frac{k-\mu_{1}}{\delta}
$$

where $\phi(r)$ is the standard normal probability density function.

Thus, in an interior solution, the marginal benefit of experimenting with $\alpha$ in terms of second-period output is equal to the marginal cost in terms of first-period output. Note that when $\mu_{1}>k$, the cost of increasing $\alpha$ is negative (the right-hand side of equation (10) is negative). Thus, when $\mu_{1}>k$, both first-period and second-period expected output are increasing in $\alpha_{1}$, and there will be a corner solution at $\alpha_{1}=1$. As shown in Antonovics and Golan (2012), the optimal level of experimentation is increasing in $\mu$; however, it is non-monotonic in the variance $\sigma$. This non-monotonicity is counterintutitive: We would expect that if you had less information you would always want to experiment more, but that is not the case. 
To understand why there is a non-monotonic relationship between $\alpha_{1}$ and $\sigma_{1}$, note that current-period expected output does not depend on $\sigma_{1}^{2}$; this finding implies that the nonmonotonic relationship between $\sigma_{1}^{2}$ and the optimal choice of $\alpha_{1}$ must depend solely on how increases in $\alpha_{1}$ affect expected future output. In particular, the effect of increasing $\alpha_{1}$ on expected future output must be low both when $\sigma_{1}^{2}$ is small and when $\sigma_{1}^{2}$ is large. When $\sigma_{1}^{2}$ is small, the option value of new information is low because new information on $\theta$ is unlikely to have a large impact on the posterior mean of $\theta$. Moreover, the expected loss of output due to incorrect future job assignments is small because the likelihood that $\theta$ is much different from $\mu_{1}$ is small. To see why the benefit of increasing $\alpha_{1}$ is also small when $\sigma_{1}^{2}$ is large, recall that an increase in $\alpha_{1}$ increases expected future output through its effect on $s_{2}^{2}$, the spread of $\mu_{2}$. As is clear from equation (6), however, $s_{2}^{2}$ is also increasing in $\sigma_{1}^{2}$ and the marginal effect of an increase in $\alpha_{1}$ on $s_{2}^{2}$ is small when $\sigma_{1}^{2}$ is large. Thus, when there is considerable uncertainty about a worker's skill, the spread of $\mu$ is large and experimentation has little value on the margin since increased information has little effect on the optimal job assignment in the second period.

While the two-period model cannot be generalized directly to a life-cycle model, intuitively, over the life-cycle the uncertainty about a worker's skill decreases, which implies, holding $\mu$ constant, that experimentation may initially increase and then decrease (for some values of $\mu$ and $\sigma$ ) based on expectations (see details and analysis of a full dynamic problem in Section 4 of Antonovics and Golan, 2012).

In our empirical work, we will use the intuition gained from the model to understand patterns of occupational choices and transitions in the data.

\section{DATA AND EMPIRICAL IMPLEMENTATION}

In our empirical work, we merge the occupational work histories from the NLSY79 to occupational characteristics from the DOT in order to construct patterns of occupational complexity and wages over workers' careers.

\subsection{The Dictionary of Occupational Titles}

The model relates the occupational returns to unobservable skills to worker experimentation; however, these returns are typically not directly observable. To create an empirical analogue of these returns, the $\alpha$ from the model, we use an index derived from occupationlevel characteristics that ranks occupations by the degree to which output depends on unobserved skills. This index was derived in Antonovics and Golan (2012) and here corresponds to our idea of occupational "complexity."

The construction of $\alpha$ relies on information in the DOT. The DOT provides information on the primary tasks performed in a given occupation and the worker characteristics necessary for successful job performance. The occupational characteristics given in the DOT are linked to the 1970 Census three-digit occupation codes in an augmented version of the April 1971 Current Population Survey compiled by the Committee on Occupational Classification and Analysis at the National Academy of Sciences. The data in the DOT are both comprehensive and detailed, describing over 12,000 occupations along 44 dimensions. 
It is important to use a list of job characteristics that captures the importance of the unknown (hard-to-observe) skill to job performance. In our model, there are several key features that characterize the unknown skill: First, there must be uncertainty about the skill prior to a worker's entry into the labor market. Second, observing output only gradually reveals a worker's skill and the more important the unobservable skill is to successful job performance, the more quickly the skill is revealed. In order to identify occupations in which hard-toobserve skill is important to job performance, we select occupational characteristics that indicate the importance of complex tasks. We define complex tasks as those for which it is hard to write down an explicit algorithm for successful completion. This is similar to the definition of "nonroutine" tasks in Autor et al. (2003).

The reasoning is that if a task can be broken into an ordered list of well-defined actions, then a worker's ability can be quickly learned by observing how the worker performs each separate action. In contrast, if it is difficult to explicitly describe how to successfully complete a task, then it will be difficult to determine a worker's skill without observing his or her on-thejob performance. $\underline{3}$ Using this list of variables, the index is created using principal component analysis. To ease comparison with the theoretical model, the index is converted into percentages. Each normalized predicted score takes on a value between zero and 1, with higher values indicating a higher level of required skill. The index is then matched to the occupation data from the NLSY79.

\subsection{The National Longitudinal Survey of Youth 1979}

In order to construct this occupational work history, we use the NLSY79, which follows individuals born between 1957 and 1964. We focus our empirical analysis on males in the cross-sectional sample. Although the NLSY79 contains information on individuals' labor force activities for each week from 1978 through the most recent year in which a respondent was interviewed, we rely only on labor market data from 1978 through 2000 because of a switch in occupational coding that occurred after 2000. If a respondent is not interviewed in a given year (or years), then at the next interview date, the respondent is asked to go back and retrospectively report their labor force activities. As a result, the NLSY79 allows us to construct relatively complete work histories. The work history data include information on each of up to five jobs a respondent may have held in a given week, and we define an individual's occupation in a given week to be their occupation in the job at which they worked the most hours.

We follow individuals' occupational histories starting with their first transition to full-time work after the completion of their highest degree. In particular, following completion of a degree, we identify the first week in which an individual works at least 10 hours per week and from which he continues to work at least 10 hours per week for at least 39 of the next 52 weeks. We then keep a running tab of the individual's actual labor market experience and occupation in each week in which he works. ${ }^{4}$ In our empirical analysis, we focus on the first 350 weeks (about 6.7 years) of each individual's actual experience in the labor force because attrition from the sample makes it difficult to construct complete work histories for longer horizons.

We take as our initial sample the cross-sectional sample of White males and the crosssectional plus supplemental sample of Black males. We lose 829 respondents because we 
Table 1

\section{Summary Statistics}

\begin{tabular}{lcccc} 
& Whites mean & $\begin{array}{c}\text { Standard } \\
\text { deviation }\end{array}$ & Blacks mean & $\begin{array}{c}\text { Standard } \\
\text { deviation }\end{array}$ \\
\hline AFQT & 62 & $(26)$ & 29 & $(23)$ \\
\hline Percent with only high school or below & 56 & $()$. & 77 & $()$. \\
\hline Hourly wage $(\$)$ & 14.58 & $(7.95)$ & 11.86 & $(7.05)$ \\
\hline Occupational $a$ & 0.54 & $(0.27)$ & 0.42 & $(0.27)$ \\
\hline Total no. of workers & 1,601 & & & \\
\hline Whites & 1,048 & & & \\
\hline Blacks & 553 & & & \\
\hline NOTE: AFQT, Armed Forces Qualification Test. & & & & \\
\end{tabular}

cannot identify either their highest degree or the date at which they received their highest degree. We additionally drop 420 respondents who completed their highest degree prior to the start date of the work-history record and 305 respondents who completed their highest degree relatively late in life, because we worry that these workers already may have accumulated substantial labor market experience that could influence employers' beliefs about skills. We also drop 36 respondents who lack information on their first week in the labor market as well as 370 respondents whose occupational histories are relatively incomplete. In particular, we drop those who either have more than 150 weeks in which they did not work or have missing occupation information during the first 500 weeks following the transition to full-time work. In other words, we give individuals 500 weeks in which to accumulate 350 weeks of valid occupation information, otherwise we drop them from the sample. We additionally drop 72 respondents who ever reported an hourly wage of either over $\$ 100$ or under $\$ 2$ and 38 respondents with missing Armed Forces Qualification Test (AFQT) scores. After these restrictions, we are left with 1,601 individuals: 553 Black and 1,048 White. Relative to the initial sample, these individuals are young and have strong attachment to the labor force.

\section{EMPIRICAL ANALYSIS}

\subsection{Racial Wage and Occupation Gaps Over the Career}

Sample summary statistics are shown in Table 1. The left (right) two columns contain mean and standard deviations for White workers' (Black workers') scores on the AFQT, the percentage of those workers with only a high school diploma or below, their hourly wages, the percentile rank of their occupation in terms of $\alpha$, and the complexity of tasks performed there. Black workers' socioeconomic background characteristics fall below White workers' for both the AFQT score and completed years of education. Black workers earn around 25 percent lower hourly wages than White workers, and controlling for education and the AFQT 


\section{Figure 1}

\section{Wage as a Function of Experience}

Mean Wage (in 2000 dollars)

16

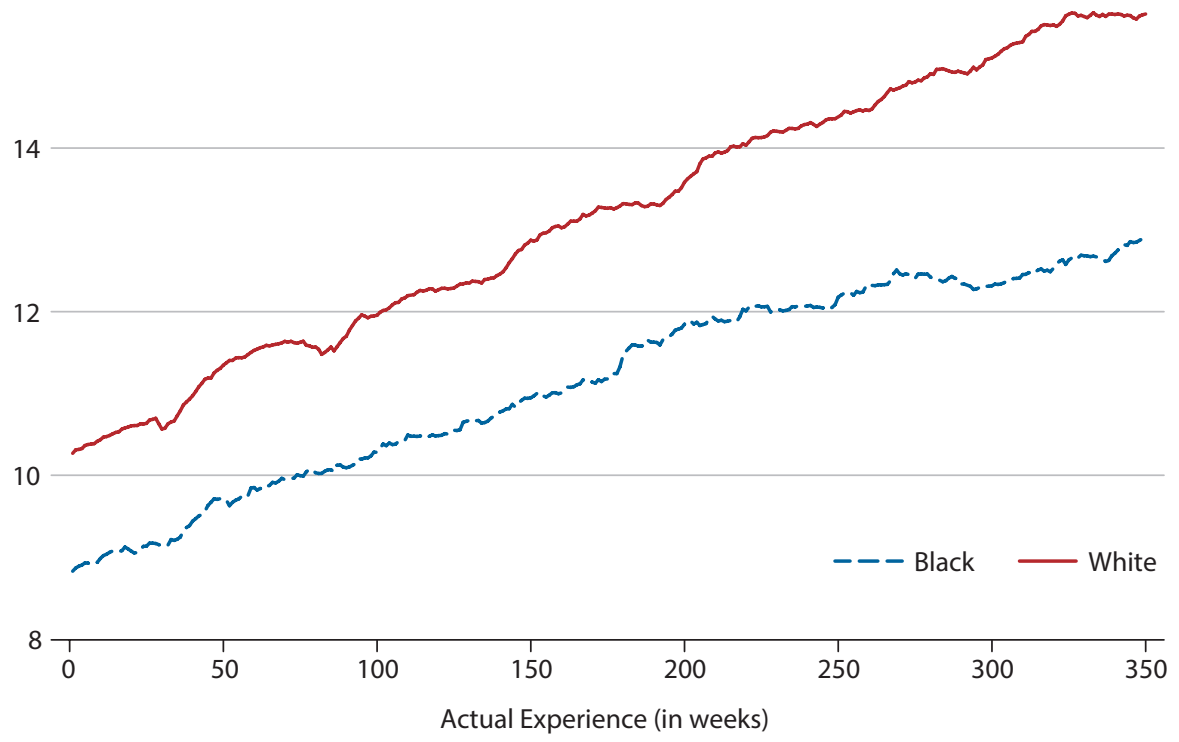

\section{Figure 2}

\section{Occupational Complexity as a Function of Experience, By Race}

Mean Alpha

0.6
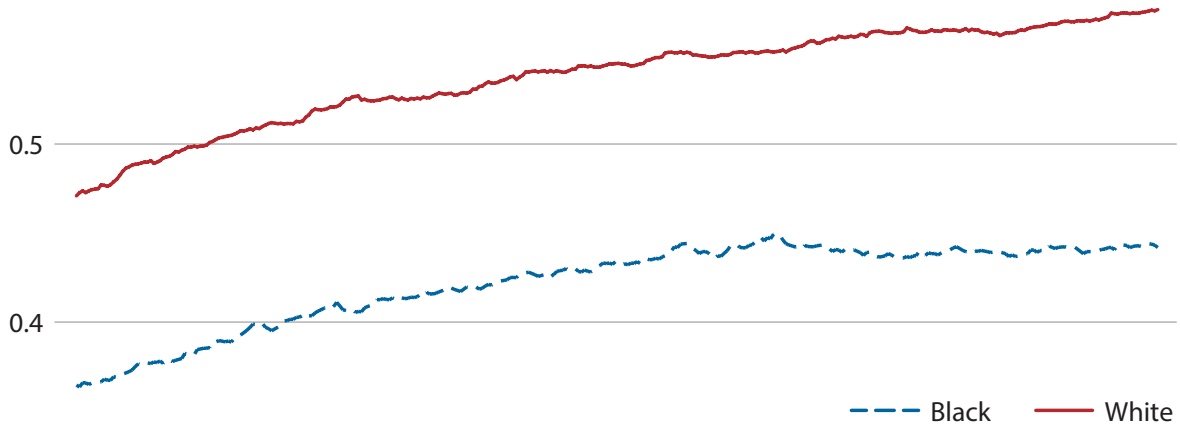

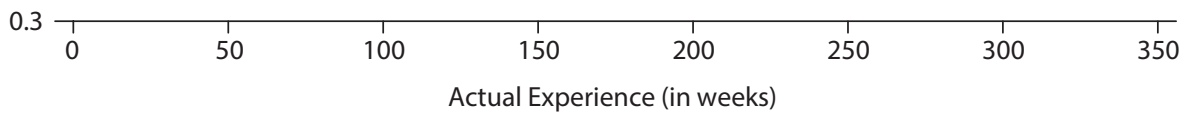


score reduces (but does not eliminate) this wage gap (see Neal and Johnson, 1996, and Lang and Modove, 2011). Less documented in the literature, Black workers tend to work in lesscomplex occupations, with the average Black worker's occupation about 10 percentage points lower in the occupation distribution than the average White worker's. As a reference point, note that the modal occupational category near the $\alpha=0.42$ average for Black workers is "trade, industrial, and technical teachers" and near the $\alpha=0.54$ average for White workers is "salesmen and sales clerks."

Differences between White and Black average wages are driven by both cross-sectional differences (at one point in the careers) and different growth rates of wages across the careers. Figure 1 shows wage levels of White and Black workers as a function of their actual labor market experiences; that is, we take the average wages of workers who we have observed in a job for exactly 50 weeks regardless of their age, the time since labor market entry, etc. As the figure shows, White workers start with hourly wages around $\$ 10.30$ compared with around $\$ 9.00$ for Black workers; and by 350 weeks of work, White workers are earning nearly $\$ 16.00$, compared with slightly less than $\$ 13.00$ for Black workers. $\cdot$

Figure 2 summarizes a less well-known pattern in labor force outcomes: Black workers begin their careers in less-complex occupations, and even by 350 weeks, the average Black worker is not even at the same job complexity as the average White worker in his first job. As in the wage-gaps graph (see Figure 1), there are differences between races in both the levels and growth rates of occupational complexity: White workers both perform higher levels of complex tasks and move over time to higher levels of complex tasks more quickly than Black workers do.

\subsection{Patterns in Occupational Mobility}

There are many possible explanations for the faster occupational-upgrading rates of White workers relative to Black workers. First, consider explanations within the class of racial discrimination: White and Black workers could face the same potential promotions and outside offers, but Black workers could be passed over more often due to discrimination at the screening phase; White and Black workers could get the same total number of opportunities to move, but White workers move up more at each transition; or Black workers could be more likely to be fired than White workers. An explanation that doesn't require any racial discrimination motive at all is simply that the growth rate of occupational complexity for workers in less-complex jobs is lower, and the lower average level of job complexity for Black workers also then explains the lower growth rate.

To get some idea about the relative merits of some of these potential explanations for the racial gap in occupational complexity, we first decompose complex-task growth over time into (i) occupation and wage changes conditional on moving jobs and (ii) the probability of moving jobs. Table 2 summarizes our results. In Panels A and B of the table, we take every week-to-week occupational transition of White workers and Black workers, respectively, and divide these into those who "move down" (move to an occupation with a lower $\alpha$ ), those who "stay" (do not change occupations or move to an occupation with an identical $\alpha$ ), and those who "move up" (move to an occupation with a higher $\alpha$ ). We also then split these weeks into 


\section{Table 2}

\section{Occupation and Wage Changes by Mover Category}

\begin{tabular}{|c|c|c|c|c|c|c|c|}
\hline A. Whites & Weeks 1-50 & $51-100$ & $101-150$ & $151-200$ & $201-250$ & $251-300$ & $310-350$ \\
\hline \multicolumn{8}{|c|}{ Move down } \\
\hline$E[\Delta a]$ & -0.22 & -0.21 & -0.21 & -0.22 & -0.21 & -0.21 & -0.21 \\
\hline$E[\Delta W](\$)$ & 1.38 & 1.11 & 1.38 & 1.52 & 1.37 & 1.33 & 1.15 \\
\hline$\sigma \Delta W(\$)$ & 4.28 & 5.60 & 4.52 & 6.65 & 6.91 & 5.50 & 5.67 \\
\hline Count & 309 & 318 & 317 & 296 & 264 & 262 & 238 \\
\hline \multicolumn{8}{|l|}{ Stay } \\
\hline$E[\Delta W](\$)$ & 0 & 0 & 0 & 0 & 0 & 0 & 0 \\
\hline$\sigma \Delta W(\$)$ & 0.42 & 0.47 & 0.48 & 0.59 & 0.76 & 0.54 & 0.60 \\
\hline Count & 44,455 & 46,837 & 47,205 & 47,355 & 47,779 & 47,657 & 47,764 \\
\hline \multicolumn{8}{|l|}{ Move up } \\
\hline$E[\Delta a]$ & 0.25 & 0.24 & 0.24 & 0.22 & 0.21 & 0.20 & 0.21 \\
\hline$E[\Delta W](\$)$ & 1.98 & 1.04 & 1.28 & 1.11 & 1.74 & 1.92 & 0.56 \\
\hline$\sigma \Delta W(\$)$ & 4.80 & 4.91 & 4.87 & 4.70 & 4.68 & 6.38 & 4.67 \\
\hline Count & 344 & 385 & 352 & 338 & 301 & 303 & 251 \\
\hline
\end{tabular}

\begin{tabular}{|c|c|c|c|c|c|c|c|}
\hline B. Blacks & Weeks 1-50 & $51-100$ & $101-150$ & $151-200$ & $201-250$ & $251-300$ & $310-350$ \\
\hline \multicolumn{8}{|c|}{ Move down } \\
\hline$E[\Delta a]$ & -0.20 & -0.21 & -0.21 & -0.21 & -0.23 & -0.22 & -0.24 \\
\hline$E[\Delta W](\$)$ & 0.58 & 1.10 & 0.30 & 0.18 & 0.68 & 1.19 & 0.81 \\
\hline$\sigma \Delta W(\$)$ & 3.20 & 3.59 & 4.63 & 4.14 & 7.23 & 4.57 & 3.82 \\
\hline Count & 164 & 209 & 174 & 152 & 174 & 172 & 141 \\
\hline \multicolumn{8}{|l|}{ Stay } \\
\hline$E[\Delta W](\$)$ & 0 & 0 & 0 & 0 & 0 & 0 & 0 \\
\hline$\sigma \Delta W(\$)$ & 0.34 & 0.54 & 0.74 & 0.73 & 0.51 & 0.67 & 0.90 \\
\hline Count & 23,256 & 24,494 & 24,805 & 24,704 & 25,116 & 25,089 & 24,925 \\
\hline \multicolumn{8}{|l|}{ Move up } \\
\hline$E[\Delta a]$ & 0.23 & 0.22 & 0.23 & 0.21 & 0.24 & 0.21 & 0.22 \\
\hline$E[\Delta W](\$)$ & 1.48 & 0.46 & 1.31 & 1.03 & 0.75 & 0.15 & 0.86 \\
\hline$\sigma \Delta W(\$)$ & 6.12 & 7.72 & 4.04 & 4.38 & 7.58 & 6.00 & 3.58 \\
\hline Count & 220 & 244 & 196 & 205 & 155 & 166 & 134 \\
\hline
\end{tabular}

NOTE: For White workers, the weekly probability of a move is 1.20 percent: 0.64 percent upward and 0.56 percent downward. For Black workers, the weekly probability of a move is 1.25 percent: 0.65 percent upward and 0.60 percent downward. 
bins based on total experience: workers in weeks 1-50, 51-100, etc. The "move down" category in the respective panels contains the average size of $\alpha$ for workers that make a downward occupational move (to a lower $\alpha$, which must by construction be negative), the average change in wages for downward occupational moves, and the standard deviation of wages for the downward occupational moves. The same statistics are computed for those who stayed in the same occupation and those who moved to a higher occupation.

Comparing Black and White workers, the two panels of Table 2 are surprisingly similar in terms of occupational moves: Given a downward occupational move, both White and Black workers move down an average of about $-.20 \alpha$ (20 percentage points) regardless of their career stage. Similarly, for those who move to a higher $\alpha$, the average size of an occupational change is about 0.21 . However, the two tables do differ in terms of the wage changes from occupational moves. Even for downward occupational moves, White workers see an average increase of around \$1.30, compared with $\$ 0.80$ for Black workers. For upward occupational moves, White workers see an average increase in wages of about $\$ 1.50$, compared with $\$ 1.00$ for Black workers. Given that the sizes of the occupational moves are the same, Black workers' wages are seemingly less sensitive to the complex tasks in a job.

The types of occupational moves Black and White workers make are similar, and the factor that explains the differences in life-cycle patterns of occupational moves is noted with Table 2: Black and White workers have almost identical weekly probabilities of switching occupations (1.20 percent for Whites and 1.25 percent for Blacks), but the relative rates of upward and downward moves differ dramatically: Given a move, White workers are 14 percent more likely to move up versus down, while Black workers are only 8 percent more likely to move up versus down.

To examine the upward versus downward mobility rates of Black and White workers in more detail, we consider transition tables across occupations, conditional on moves. Table 3 is constructed to show these rates: We take every occupational transition (and ignore "stayers"), group the "pre-move" and "post-move" occupations into 10 bins, and calculate the conditional probability of a worker being in in some post-move bin given the worker's pre-move occupation. So by construction, the rows sum to 1 and reading across a row gives the probabilities of moving into that bin given the row. This table helps deal with differences in the average occupations between White and Black workers: Now we can compare the occupational moves of a White worker and a Black worker who begin in the same occupation, which will help control for potential demographic and unobserved differences between them.

The overall results from Table 3 show that conditional on a worker's current occupation, the race of the worker matters strongly when predicting to which occupations he will move to next. Take a White worker and a Black worker both in the occupation "sales," which has $0.42 \alpha$, putting them in the " 0.5 " row. At his next move, the White worker ends up in a morecomplex-task job 37 percent of the time. The Black worker, however, ends up at a higher- $\alpha$ job only 25 percent of the time. $\frac{6}{}$ This pattern is repeated across almost every row: low-occupation White workers move up faster than low-occupation Black workers, and high-occupation White workers downgrade less than high-occupation Black workers.

Interpreting these transition matrices within our model, given a worker is in a particular occupation in one period, there are two reasons he can be in a different occupation the next 


\section{Table 3}

\section{Transition Matrices}

\begin{tabular}{|c|c|c|c|c|c|c|c|c|c|c|c|}
\hline & 0.1 & 0.2 & 0.3 & 0.4 & 0.5 & 0.6 & 0.7 & 0.8 & 0.9 & 1.0 & Count \\
\hline \multicolumn{12}{|c|}{ Whites } \\
\hline 0.1 & 0.18 & 0.16 & 0.14 & 0.16 & 0.17 & 0.07 & 0.06 & 0.04 & 0.01 & 0.02 & 539 \\
\hline 0.2 & 0.20 & 0.12 & 0.17 & 0.14 & 0.14 & 0.09 & 0.08 & 0.04 & 0.02 & 0.01 & 406 \\
\hline 0.3 & 0.16 & 0.13 & 0.15 & 0.09 & 0.16 & 0.09 & 0.11 & 0.06 & 0.02 & 0.02 & 418 \\
\hline 0.4 & 0.16 & 0.11 & 0.10 & 0.09 & 0.16 & 0.12 & 0.09 & 0.11 & 0.03 & 0.04 & 448 \\
\hline 0.5 & 0.15 & 0.12 & 0.12 & 0.11 & 0.14 & 0.10 & 0.12 & 0.09 & 0.03 & 0.03 & 485 \\
\hline 0.6 & 0.08 & 0.05 & 0.08 & 0.10 & 0.12 & 0.13 & 0.09 & 0.15 & 0.11 & 0.09 & 415 \\
\hline 0.7 & 0.06 & 0.05 & 0.09 & 0.07 & 0.07 & 0.13 & 0.12 & 0.19 & 0.08 & 0.15 & 430 \\
\hline 0.8 & 0.06 & 0.01 & 0.05 & 0.06 & 0.09 & 0.13 & 0.13 & 0.21 & 0.11 & 0.16 & 467 \\
\hline 0.9 & 0.03 & 0.01 & 0.02 & 0.04 & 0.05 & 0.12 & 0.09 & 0.22 & 0.14 & 0.28 & 292 \\
\hline 1.0 & 0.01 & 0.02 & 0.01 & 0.02 & 0.03 & 0.10 & 0.17 & 0.19 & 0.19 & 0.27 & 378 \\
\hline \multicolumn{12}{|c|}{ Blacks } \\
\hline 0.1 & 0.27 & 0.14 & 0.19 & 0.12 & 0.14 & 0.05 & 0.03 & 0.04 & 0 & 0.01 & 560 \\
\hline 0.2 & 0.29 & 0.11 & 0.20 & 0.13 & 0.10 & 0.03 & 0.07 & 0.06 & 0 & 0.01 & 269 \\
\hline 0.3 & 0.28 & 0.11 & 0.15 & 0.14 & 0.12 & 0.08 & 0.07 & 0.03 & 0.01 & 0.01 & 375 \\
\hline 0.4 & 0.17 & 0.09 & 0.12 & 0.16 & 0.19 & 0.09 & 0.05 & 0.07 & 0.03 & 0.03 & 329 \\
\hline 0.5 & 0.23 & 0.14 & 0.19 & 0.15 & 0.07 & 0.06 & 0.05 & 0.07 & 0.03 & 0.02 & 296 \\
\hline 0.6 & 0.16 & 0.08 & 0.13 & 0.18 & 0.10 & 0.05 & 0.09 & 0.11 & 0.08 & 0.02 & 171 \\
\hline 0.7 & 0.10 & 0.06 & 0.19 & 0.06 & 0.11 & 0.05 & 0.13 & 0.11 & 0.14 & 0.06 & 145 \\
\hline 0.8 & 0.09 & 0.04 & 0.07 & 0.14 & 0.10 & 0.09 & 0.09 & 0.17 & 0.07 & 0.14 & 162 \\
\hline 0.9 & 0.02 & 0.02 & 0.05 & 0.09 & 0.10 & 0.13 & 0.13 & 0.15 & 0.15 & 0.16 & 93 \\
\hline 1.0 & 0.02 & 0.03 & 0.05 & 0.04 & 0.04 & 0.07 & 0.10 & 0.16 & 0.16 & 0.34 & 106 \\
\hline
\end{tabular}

NOTE: Bolded entries represent the conditional median of post-move $a$ given pre-move $a$.

period: First, he learned that another occupation is a better fit, and/or second, the value of experimentation has changed after learning in the first period. For example, if Black workers in high-complexity occupations are in those occupations because they are informative, whereas they are the best matches for the average White worker, you are more likely to see Black workers leave those occupations as they learn more and have less incentive to experiment further. Discrimination adds a further level of complexity because Black workers may be restricted from entering their preferred occupations, so the incentives to learn may be the same but they may be being restricted from finding their best match as quickly as White workers. Using a structural life-cycle model, we further investigate the roles of productivity, learning, and discrimination in Golan et al. (2017). 
Table 4

The Relationship Between Wage Growth and Initial Job Assignment

\begin{tabular}{lcc} 
& $(1)$ & $(2)$ \\
Dependent variable: wages & Blacks & Whites \\
\hline Initial wage & $0.596^{* * *}$ & $0.674^{* * *}$ \\
& $(0.044)$ & $(0.038)$ \\
\hline Initial $a$ & 0.880 & 0.358 \\
& $(0.747)$ & $(0.634)$ \\
\hline Actual experience (in years) & $0.508^{* * *}$ & $0.954^{* * *}$ \\
& $(0.149)$ & $(0.127)$ \\
Initial wage $\times$ actual & $-0.032^{* *}$ & $-0.045^{* * *}$ \\
experience & $(0.016)$ & $(0.015)$ \\
\hline Initial $a \times$ actual experience & $1.267^{* * *}$ & $1.130^{* * * *}$ \\
\hline AFQT & $(0.264)$ & $(0.190)$ \\
\hline Constant & $1.532^{* * *}$ & $1.330^{* * *}$ \\
& $(0.286)$ & $(0.185)$ \\
\hline Observations & $2.320^{* * *}$ & $0.805^{* * *}$ \\
\hline$R^{2}$ & $(0.346)$ & $(0.410)$ \\
\hline & & \\
NOTE: Robust standard errors are in parentheses. & & \\
\hline$* 0.05$. & & 343,620 \\
\hline
\end{tabular}

\section{Table 5}

\section{Determinants of an Initial Job Assignment}

\begin{tabular}{|c|c|c|}
\hline Dependent variable: wages & $\begin{array}{c}(1) \\
\text { Initial } a\end{array}$ & $\begin{array}{c}\text { (2) } \\
\text { Initial wage }\end{array}$ \\
\hline Initial $a$ & & $\begin{array}{l}3.477^{* * * *} \\
(0.555)\end{array}$ \\
\hline Years of schooling (0 to 7 ) & $\begin{array}{l}0.057^{* * *} \\
(0.004)\end{array}$ & $\begin{array}{l}0.572^{* * * *} \\
(0.111)\end{array}$ \\
\hline Age & $\begin{array}{l}0.014^{* * * *} \\
(0.002)\end{array}$ & $\begin{array}{l}0.168^{* * * *} \\
(0.055)\end{array}$ \\
\hline Black & $\begin{array}{c}-0.026^{*} \\
(0.015)\end{array}$ & $\begin{array}{c}-0.312 \\
(0.324)\end{array}$ \\
\hline AFQT & $\begin{array}{l}0.068^{* * *} \\
(0.008)\end{array}$ & $\begin{array}{l}0.440^{* * *} \\
(0.175)\end{array}$ \\
\hline Constant & $\begin{array}{c}-0.128 \\
(0.049)\end{array}$ & $\begin{array}{l}3.340^{* * * *} \\
(1.070)\end{array}$ \\
\hline Observations & 1,593 & 1,593 \\
\hline$R^{2}$ & 0.376 & 0.189 \\
\hline
\end{tabular}

\subsection{Initial Job Assignment}

In the context of a learning model, the initial job assignment has an outsized effect on the career path. If workers start their careers in a job or occupation where they learn nothing about themselves, their wages would grow only as a result of human capital growth or other factors. On the other hand, workers beginning in very informative jobs will see their wages grow on average as they become better matched. If more-complex jobs also reveal more about a worker's innate ability, there should be a positive relationship between the measure of complexity in a worker's initial job and future wage growth.

In Table 4 we consider the relationship between characteristics of a worker's first job and future wage growth. The dependent variable is the pooled cross section of wages in all jobs after the first job, while the independent variables include both initial wages and initial $\alpha$, actual labor market experience, and interactions between initial job characteristics and actual experience. The model has no particular predictions for the relationship between the initial $\alpha$ and wages, but it predicts that the coefficient on the interaction of the initial $\alpha$ and experience will be positive, which is what the data show. To interpret the estimates, relative to the wage growth of a worker at the Black-worker sample average of $\alpha=0.42$, a worker at the White-worker 
sample average of $\alpha=0.54$ would see faster average wage growth of about $\$ 0.13$ per year. That is, there is around a 1 percent difference in the average yearly rates of wage growth that can be attributed to racial differences in occupational characteristics.

Differences in information about one's own ability can be reflected as well in the choice of initial occupation: Workers with more to learn about themselves would tend toward occupations that provide more information. In Table 5 we document the relationship between worker characteristics and the complexity measure $\alpha$ and the wage of the worker's first job. In the first column, the dependent variable is the complexity of the initial occupation, and we condition on education, age, race, and AFQT score. Even after the controls for ability, provided by controlling for education and the AFQT score, we find that Black workers start their careers in about 2 percentage point less-complex-task occupations. While this may seem small, it can be compared with the effect of lowering a worker's AFQT score by $1 / 3$ of a standard deviation, which is a substantial drop. On the other hand, in the second column of Table 5 we find little evidence of a direct effect of race on the wage of the initial job once $\alpha$ and the ability measures have been controlled for.

The finding that Black workers end up in less-complex jobs than comparable White workers all while earning effectively the same as those White workers can be interpreted in multiple ways consistent with our model of worker learning. For one, say discrimination is the reason that Black workers don't have access to more-complex jobs. This will reduce the amount of learning Black workers have about themselves relative to what White workersin more-informative occupations-have about themselves. The long-run effect of the initial discrimination would be that Black workers' wage growth is lower relative to White workers' wage growth than it would otherwise be if both races were assigned the same $\alpha$ jobs initially.

\section{CONCLUSION}

This article documents racial gaps in occupational assignment, turnover, and wages. We use a learning model in which there is uncertainty about skills early in a worker's career to interpret the empirical evidence on the economic forces behind occupation mobility and the Black-White pay gap and its evolution over a worker's career.

We first document that both wage and occupation racial gaps increase with worker experience. Occupational turnover is on average associated with an increase in pay. This is true even for transitions from high- to low-skill-requirement occupations. Our learning model is consistent with this pattern because it implies that workers sort into jobs that better match their skills. This pattern holds for both Black and White individuals. Furthermore, we find no significant differences in the number of occupational moves for Black and White workers. However, Black workers are more likely to transition into occupations with lower skill requirements than White workers and therefore experience smaller wage growth. This pattern is also consistent with the widening gap in occupational skill requirements between Black and White workers.

To further explore the Black-White wage gaps, we focus on differences in initial occupational assignments. The learning model presented predicts that workers assigned initially to 


\section{Golan and Sanders}

more-complex jobs will experience faster wage growth than those assigned initially to lesscomplex jobs, because those in more-complex jobs will have more ability to learn about their best occupation. Again, our analysis demonstrates that this pattern empirically holds for both Black and White individuals. However, Black workers are assigned initially to jobs with lower complexity partly because they have different demographic characteristics when they enter the labor market, such as lower educational attainment and lower AFQT scores. Nevertheless, we show that AFQT scores and educational attainment do not explain the entire gap in initial occupational assignments. This finding can be interpreted both as differences in beliefs and learning, but can at the same time be consistent with discriminatory hiring practices.

For future research, we suggest that further analyses should focus on understanding the interaction between discrimination and learning, since restricting workers from entering their preferred occupation as young workers can have lifetime effects on earnings and potentially be an important source of racial inequality.

\section{NOTES}

12016 Current Population Survey, Bureau of Labor Statistics.

$\underline{2}$ This index was created in Antonovics and Golan (2012).

3 For details and examples, see Antonovics and Golan (2012).

4 In this tabulation, after making the sample selection rules discussed below, we treat individuals with missing occupation information as being out of the labor force.

5 An alternative specification of these graphs uses worker age on the horizontal axis, which makes the gaps marginally larger and increasing over time, since differences in actual experience between White and Black workers grow over time. See Golan et al. (2017) for a discussion of the effects of labor market participation rates on wage and occupation gaps.

6 This calculation is done by summing all elements of the row to the right of the " 0.5 " column.

\section{REFERENCES}

Altonji, J.G. and Blank, R.M. "Race and Gender in the Labor Market," in O. Ashenfelter \& D. Card, eds., Handbook of Labor Economics. Edition 1, Volume 3. Elsevier, 1999, pp. 3143-259.

Altonji, J.G. and Pierret, C.R. "Employer Learning and Statistical Discrimination." Quarterly Journal of Economics, 2001, 116(1), pp. 313-50; https://doi.org/10.1162/003355301556329.

Antecol, H. and Bedard, K. "The Racial Wage Gap the Importance of Labor Force Attachment Differences Across Black, Mexican, and White Men." Journal of Human Resources, 2004, 39(2), pp. 564-83; https://doi.org/10.2307/3559027.

Antonovics, K. and Golan, L. “Experimentation and Job Choice." Journal of Labor Economics, 2012, 30(2), pp. 333-66; https://doi.org/10.1086/663356.

Autor, D.H.; Levy, F. and Murnane, R.J. "The Skill Content of Recent Technological Change: An Empirical Exploration." Quarterly Journal of Economics, 2003, 118(4), pp. 1279-333; https://doi.org/10.1162/003355303322552801.

Brown, C. "Black-White Earnings Ratios Since the Civil Rights Act of 1964: The Importance of Labor Market Dropouts." Quarterly Journal of Economics, 1984, 99(1), pp. 31-44; https://doi.org/10.2307/1885719.

Cameron, S. V. and Heckman, J.J. "The Dynamics of Educational Attainment for Black, Hispanic, and White Males." Journal of Political Economy, 2001, 109(3), pp. 455-99; https://doi.org/10.1086/321014. 
Carneiro, P.; Heckman, J.J. and Masterov, D.V. "Labor Market Discrimination and Racial Differences in Premarket Factors." Journal of Law and Economics, 2005, 48(1), p. 1; https://doi.org/10.1086/426878.

Chandra, A. "Labor-Market Dropouts and the Racial Wage Gap: 1940-1990." American Economic Review, 2000, 90(2), pp. 333-38; https://doi.org/10.1257/aer.90.2.333.

Eckstein, Z. and Wolpin, K.I. "Estimating the Effect of Racial Discrimination on First Job Wage Offers." Review of Economics and Statistics, 1999, 81(3), pp. 384-92; https://doi.org/10.1162/003465399558319.

Farber, H. and Gibbons, R. "Learning and Wage Dynamics." Quarterly Journal of Economics, 1996, 111(4), pp. 1007-47; https://doi.org/10.2307/2946706.

Fryer, R.G. "Racial Inequality in the 21st Century: The Declining Significance of Discrimination." Handbook of Labor Economics, 2011, 4, pp. 855-971; https://doi.org/10.1016/S0169-7218(11)02408-7.

Gibbons, R.; Katz, L.F.; Lemieux, T. and Parent, D. “Comparative Advantage, Learning, and Sectoral Wage Determination." Journal of Labor Economics, 2005, 23(4), pp. 681-724; https://doi.org/10.1086/491606.

Gibbons, R. and Waldman, M. "A Theory of Wage and Promotion Dynamics Inside Firms." Quarterly Journal of Economics, 1999, 114(4), pp. 1321-58; https://doi.org/10.1162/003355399556287.

Golan, L.; Sanders, C. and James, J. “The Black-White Wage Gap Over the Life Cycle." Working Paper, 2017.

James, J. “Learning and Occupational Sorting." Working paper, California State Polytechnic, 2012.

Jovanovic, B. "Job Matching and the Theory of Turnover." Journal of Political Economy, 1979, 87(5, Part 1), pp. 972-90; https://doi.org/10.1086/260808.

Juhn, C. "Labor Market Dropouts and Trends in the Wages of Black and White Men." Industrial and Labor Relations Review, 2003, 56(4), pp. 643-62; https://doi.org/10.1177/001979390305600406.

Lang, K. and Manove, M. "Education and Labor Market Discrimination." American Economic Review, 2011, 101(4), pp. 1467-96; https://doi.org/10.1257/aer.101.4.1467.

Miller, R.A. "Job Matching and Occupational Choice." Journal of Political Economy, 1984, 92(6), pp. 1086-120; https://doi.org/10.1086/261276.

Neal, D. “The Complexity of Job Mobility Among Young Men." Journal of Labor Economics, 1999, 17(2), pp. 237-61; https://doi.org/10.1086/209919.

Neal, D.A. and Johnson, W.R. "The Role of Premarket Factors in Black-White Wage Differences." Journal of Political Economy, 1996, 104(5), pp. 869-95; https://doi.org/10.1086/262045.

Oettinger, G.S. "Statistical Discrimination and the Early Career Evolution of the Black-White Wage Gap." Journal of Labor Economics, 1996, 14(1), pp. 52-78; https://doi.org/10.1086/209803.

Papageorgiou, T. "Learning Your Comparative Advantages." Review of Economic Studies, 2014, 81(3), pp. 1263-95; https://doi.org/10.1093/restud/rdt048.

Pastorino, E. "Learning in Labor Markets and Job Mobility." Unpublished manuscript, Department of Economics, University of lowa, 2009.

Sanders, C. "Skill Accumulation, Skill Uncertainty, and Occupational Choice." Working paper, Washington University in St. Louis, 2017

Sanders, C. and Taber, C. "Life-Cycle Wage Growth and Heterogeneous Human Capital." Annual Review of Economics, 2012, 4(1), pp. 399-425; https://doi.org/10.1146/annurev-economics-080511-111011.

Western, B. and Pettit, B. "Black-White Wage Inequality, Employment Rates, and Incarceration." American Journal of Sociology, 2005, 111(2), pp. 553-78; https://doi.org/10.1086/432780. 
